\title{
Melasma Review of current treatment modalities and efficacy assessment of a new resorcinol-based topical formulation
}

\author{
Kaliterna D \\ Polyclinic Poliderma, Croatia
}

\begin{abstract}
Melasma is one of the most common pigmentary disorders characterized by symmetrical pigmented macules on the face. It most commonly affects women of reproductive age with darker complexions, and has a considerable impact on quality of life. The pathogenesis of melasma is complex and involves various risk factors such as genetic predisposition, UV exposure, darker phototype and hormonal influence. Taking into account its chronic and relapsing course, as well as the fact that despite numerous treatment modalities available, no single treatment option has proven to be efficient for all patients with melasma, the treatment still remains a challenge. This paper provides a review of the current literature on melasma treatment and presents the results of a study assessing a new promising resorcinol-based topical formulation with better efficacy and safety profile than other currently available treatment options for melasma.
\end{abstract}

\section{Introduction}

Melasma (from the Greek word "melas" meaning black) is an acquired hyperpigmentation of the skin, typically affecting the sunexposed areas of the face, occasionally occurring on the neck, and rarely on the forearms. The term, "chloasma" (from the Greek word "chloazein" meaning green) is used to describe melasma developing during pregnancy (but since the pigmentation is never green, the term, "melasma" is preferred) [1,2].

It presents clinically as symmetrical hyperpigmented macules on the face (the color varies from light brown to bluish gray depending on the depth of melanin deposition). There are usually three patterns of involvement: centrofacial (involves the cheeks, forehead, upper lip, nose, chin), malar (involves the cheeks and nose), and mandibular (involves the mandible) [3] (Figure 1).

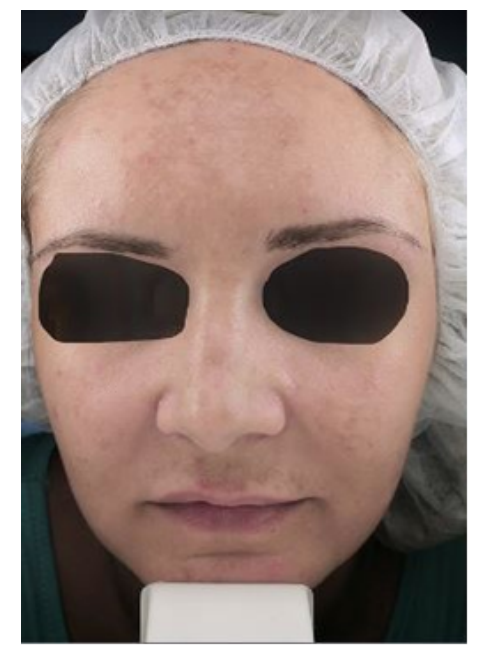

Figure 1. Image showing centrofacial pattern of melasma involvement
It is a common disorder affecting millions of people worldwide, with the exact prevalence varying between $1,5 \%$ and $33,3 \%$, depending on the population. Melasma most commonly affects women of reproductive age with darker complexions (Fitzpatrick skin type IVVI), although it can also be seen in men. Among pregnant women, prevalence can be up to $70 \%$. Melasma of the pregnancy usually improves a year after delivery, but areas of hyperpigmentation may never completely resolve. Taking into account the facial involvement, melasma has a considerable impact on the quality of life of the affected individuals [4-7].

The pathogenesis of melasma is complex and still not well understood. Known risk factors include genetic predisposition, ultraviolet (UV) radiation exposure, darker phototype, hormonal influence (pregnancy, oral contraceptives, increased levels of luteinizing hormone, thyroid disease), and certain medications such as phenytoin $[5,7]$.

It is known that UV radiation induces melanocyte proliferation. Although the number of melanocytes is similar in lesional and perilesional skin, melasma may be caused by biologically more active melanocytes in the affected skin [8]. In melasma lesions, there are increased stem cell factor from fibroblast and tyrosine kinase receptor c-kit, as well as the expression of vascular endothelial growth factor (VEGF). Direct role of VEGF in pathogenesis of melasma is supported by the observation of increased number and size of blood vessels in melasma lesions, as well as by the finding that human melanocytes in vitro express VEGF receptors. This warrants investigation of new treatment options to target the vascular component of melisma [5,9-11] (Figure 2).

Correspondence to: Dinko Kaliterna, Polyclinic Poliderma, Croatia, E-mail: poliderma@poliderma.hr

Key words: melasma, resorcinol, pigmentary disorders, melasma treatment

Received: June 14, 2017; Accepted: June 25, 2017; Published: August 07, 2017 


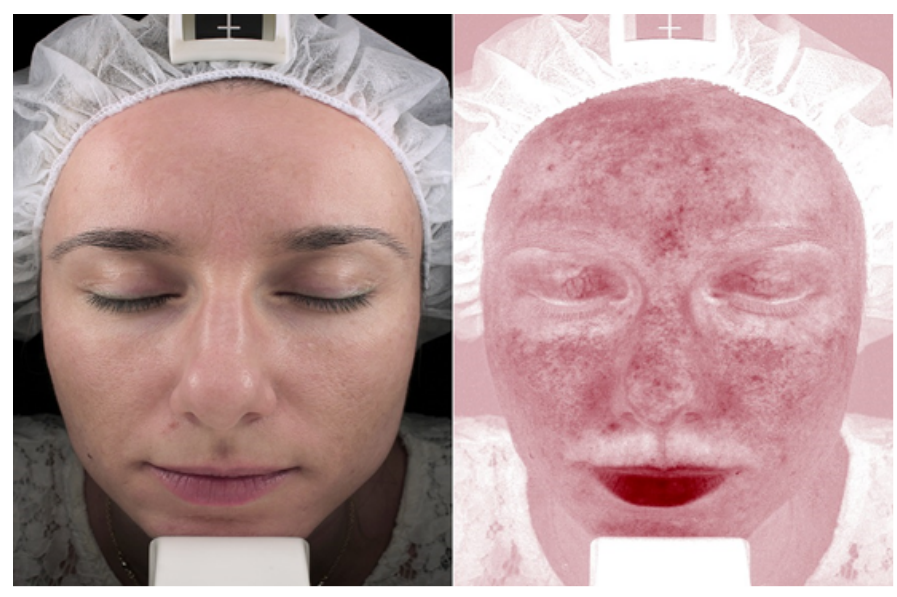

Figure 2. Image using VISIA analysis - in the areas of hyperpigmentations, there is increased number and size of blood vessels.

Histopathology of melasma lesion shows an increased melanin deposition in all layers of epidermis, with elastosis and mast cells more pronounced than in normal skin $[12,13]$. The most affected biological process is lipid metabolism- there is downregulation of various lipid metabolism genes caused by chronic UV exposure [14,15].

Melasma is traditionally classified according to the depth of distribution of melanin pigment in three types [16]:

1. Epidermal (light brown, enhancement of contrast with Wood's light) - melanin is deposited in basal and suprabasal epidermis. Shows good response to treatment.

2. Dermal (bluish gray, no enhancement of contrast with Wood's light) - melanin laden macrophages in superficial and mid-dermis. Shows poor response to treatment.

3. Mixed (dark brown, partial enhancement of contrast with Wood's light) - melanin is deposited epidermis and dermis. Partial response to treatment.

Examination with a Wood's lamp can be used to determine the location of the pigment, but is limited in detecting dermal melanin composition [16]. The severity of melasma may be assessed by using melasma area and severity index (MASI) or Melasma Severity Index (MSI) [17].

Taking into account the chronic and relapsing nature of melasma, as well as the fact that no single treatment option has proven to be efficient for all patients with melasma, the treatment may be challenging. Before choosing the treatment modality, analysis of the characteristics of melasma lesion is recommended. This can be performed by VISIA or other similar systems. The area most responsive to treatment is the forehead, while other locations and older lesions seem to be more refractory. Current treatment options include the following:

1. Prevention of UV radiation (photoprotection). No matter the chosen treatment modality, sun protection measures are a necessity (sun avoidance, wide-brimmed hat, using broad-spectrum sunscreens during and after the treatment).

2. Hydroquinone is a gold standard of treatment of epidermal melasma, although its effects are reversible. It inhibits conversion of DOPA to melanin by inhibiting tyrosinase [4]. It is used as a topical preparation in various concentrations from $2-5 \%$ (higher concentration may be more effective, but associated with erythema, skin peeling, irritant contact dermatitis, hypopigmentation of the surrounding skin, development of milia, and exogenous ochronosis [18]. Its long-term safety has been widely debated. EU has banned its use as a cosmetic ingredient, but prescription hydroquinone is still available to patients [19].

3. Azelaic acid is derived from $P$. Ovale and is a weak reversible competitive inhibitor of tyrosinase. It has anti-proliferative action and is selectively cytotoxic towards hyperactive melanocytes, with minimal effects on normally pigmented skin [1]. It is available in $20 \%$ cream or $15 \%$ gel formulations. In several studies it was compared to hydroquinone, with similar efficacy but significantly more side effects such as erythema burning, pruritus and scaling [20-22].

4. Ascorbic acid (vitamin C) is reported treatment for melasma due to its ability to chelate copper ions. It does not work well as monotherapy, it is highly unstable and rapidly oxidised. It may be a good treatment adjunct in patients who cannot tolerate hydroquinone, since it causes less irritation.

5. Kojic acid is produced by A. oryzae and Penicillium spp. and inhibits tyrosinase [4]. It is used in combination with hydroquinone and glycolic acid. Kojic acid can substitute for hydroquinone if a patient is intolerant to hydroquinone [1]. Adverse effects include local irritation and contact dermatitis, as it is a known sensitizer.

6. Topical retinoids act by stimulation of keratinocyte turnover and decreasing melanosome transfer. Treatment is contraindicated during pregnancy.

- Tretinoin has shown to be efficacious treatment for melasma, but the dermal pigment after the therapy remains unchanged. Its use as a monotherapy is unlikely to be as effective as hydroquinone or combination therapy, being limited by side-effects including erythema and irritation $[23,4]$.

- Adapalene is a synthetic retinoid that causes less cutaneous irritation than other retinoids, and is more appropriate for longterm use [4].

\section{Topical combination treatments}

- The Kligman-Willis formula (5\% hydroquinone, $0,1 \%$ tretinoin, $0,1 \%$ dexamethasone) was one of the first combination treatments developed for hyperpigmentation over 30 years ago. This combination minimizes side effects and maximizes effect in shorter period of time than when the ingredients are used individually.

- The triple therapy combination (TCC) contains $4 \%$ hydroquinone, $0,05 \%$ tretinoin and $0,01 \%$ fluocinolone acetonide. It has proven to be fairly efficacious in melasma treatment, but with often present side-effects such as erythema, irritation, burning, and xerosis, as well as a risk of postinflammatory hyperpigmentation $(\mathrm{PIH})$ in patients with darker skin color [4].

- Other combinations were also evaluated with varying success (hydroxyquinone, hyaluronic acid, glycolic acid, ascorbic acid, kojic acid) - usually show greater efficacy than individual treatments [24-26].

8. Chemical peels are usually recommended to patients unresponsive to skin-lightening treatments, and show mixed results for melasma treatment. There are three types of chemical peels: superficial, medium, and deep (more adverse effects occur with deeper peels). They are mostly used in Caucasians, and are most useful for treating epidermal-type melasma, although recurrences are 
frequent. In patients with darker skin types, there is a risk of PIH. Various formulations exist [25].

- Glycolic acid (GA) is used in concentrations from 20 to $70 \%$. It is best used in combination with other topical treatments [4]. When in high concentrations it should be used with caution in darker skin types, but is the safest and the most efficacious peel in low concentrations in this group of patients.

- Salicylic acid has anti-inflammatory and diffuse whitening effect, but is not as effective as hydroquinone [27].

- Trichloroacetic acid (TCA) peels are used in concentrations between $10-20 \%$ in lighter skin types and show good results, but should be used with caution in darker skin types due to a risk of postinflammatory hyperpigmentation and scarring.

- Other peels such as pyruvic acid, combination SA and mandelic, phytic acid, Obagi blue and amino fruit acid, show various results and there is little published evidence supporting their everyday use for melasma treatment.

9. Laser therapy. Numerous studies have demonstrated good efficacy of laser therapy for melasma treatment [28]. Main adverse effects are erythema, burning, dryness, scaling, edema, rebound hyperpigmentations, hypopigmentations, depigmentations, physical urticaria, acneiform eruption, petechiae, and herpes simplex reactivation [29]. Lasers currently used for melasma treatment are the following [1];

- Q switched nd:YAG (1064nm) is most widely used for melasma treatment. It penetrates deeply, targets dermal melanin, and mininmally damages epidermis. Fluence used is less than $5 \mathrm{~J} / \mathrm{cm} 2$, spot size $6 \mathrm{~mm}$, and frequency of $10 \mathrm{~Hz}$. The number of treatment sessions varies from 5 to 10 at 1-week intervals. When "laser toning" technique is used with good efficacy but possible side effects, the parameters are large spot size $(6-8 \mathrm{~mm})$, low fluence (1.6-3.5 J/cm2), and multiple passes with QS $1064 \mathrm{~nm} \mathrm{Nd:} \mathrm{YAG}$ laser are performed every 1-2 weeks for several weeks [1].

- Q switched ruby $(694 \mathrm{~nm})$ is more selective for melanin, the fluence used is $2-7 \mathrm{~J} / \mathrm{cm} 2$, but the results in studies are controversial.

- Q switched alexandrite $(755 \mathrm{~nm})$

- Er:YAG (2940nm) shows higher incidence of PIH [30], and the fluence used is $5-8 \mathrm{~J} / \mathrm{cm} 2$.

- PDL (585nm) targets vascular component of melasma and shows low rate of relapses. The fluence used is $7-10 \mathrm{~J} / \mathrm{cm} 2$.

- Fractional laser $(1550 \mathrm{~nm})$ penetrates deeper (dermal melasma can be targeted) and does not create open wounds (less complications and faster recovery rate).

10. Intense pulsed light (IPL) uses non-coherent broadbspectrum light $(500-1200 \mathrm{~nm})$. It is effective for epidermal melasma, although recurrences are common [31]. Also higher fluences are needed, and there is a risk of PIH in darker skin types.

11. Tranexamic acid is a lysine analog that has been in use as antifibrinolytic agent for 30 years. It acts by inhibiting UVinduced plasmin activity in keratinocytes by preventing binding of plasminogen to keratinocytes - this results in decreased melanocyte tyrosinase activity, and hence reduced pigmentation [32,1]. It also inhibits plasmin, which converts extracellular matrix-bound VEGF into its free forms [33]. Tranexamic acid can be used orally (250mg $2 \mathrm{x}$ daily), topically, or by intradermal microinjection [34]. As an oral therapy, its effect was investigated in 74 Chinese patients and the evaluated improvement of pigmentation was excellent in $10,8 \%$, good in $54 \%$, fair in $31,1 \%$ and poor in $4,1 \%$ patients. Side effects were gastrointestinal discomfort and hypomenorrhea, and recurrence was seen in 9,5\% patients [35]. As a topical preparation, it did not prove to be very effective, but intradermal application showed significant decrease in MASI score and minimal side effects [36,37].

12. Oligopeptides are a new class of tyrosinase inhibitors with good efficacy and safety profile [38,39].

13. Silymarin is a polypeptide plant-derived flavonoid with antioxidant properties. It reduces the harmful effects of UV radiation and also inhibits melanin production in a dose-dependent manner [40]. It is in cream formulation with various concentrations. One study showed good improvement with no adverse effects [1].

14. Orchid extracts and various botanical extracts - grape seed extract, pycnogenol, aloesin, green tea extracts, coffee berry, soy, and licorice extract [41].

\section{Materials and methods}

A study was conducted in a Clinic in Zagreb according to the protocol and in accordance with ethical guidelines. The study included 30 female volunteers of 25 to 45 years of age, diagnosed with melasma. The volunteers were either treatment naïve or had not used any treatment modality for melasma for at least 6 months. The exclusion criteria included any treatment for melasma within past 6 months, hypersensitivity to resorcinol or any other ingredient of the formulation, pregnancy, and any type of facial skin damage, disease, or infection.

The volunteers were given a cream based on resorcinol derivative at a baseline visit, and were instructed to apply a small amount of cream once daily on a clean face at bedtime, during a period of 30 days. They were also instructed to avoid sun exposure and apply sunscreens.

The efficacy of the treatment was done using the VISIA image analysis. The images were taken before the treatment, and again after 30 days.

\section{Results}

A total of 30 volunteers were included in a study. No subjects were lost to follow-up, and all of them reported compliance to the protocol. 27 out of 30 subjects reported satisfaction with the results. Of those, 20 were extremely satisfied with results, and 7 were very satisfied. Aside from significant reduction in hyperpigmentation, they reported improved skin quality and texture, as well as reduction in skin pores. 2 out of 30 patients reported moderate satisfaction with results, while 1 patient reported that she is not satisfied.

No severe side effects were reported. Only 2 volunteers reported irritation or burning sensation during a few days after cream application, but spontaneous resolution of symptoms after a few minutes. Most of the clients reported first visible change and improvement between days 7 and 10.

The following are the images using VISIA on day 1 and day 30 (Figure 3).

Image using VISIA analysis: reduction in superficial hyperpigmentation (Figure 4).

Image using VISIA analysis: reduction in deep hyperpigmentation (Figure 5). 

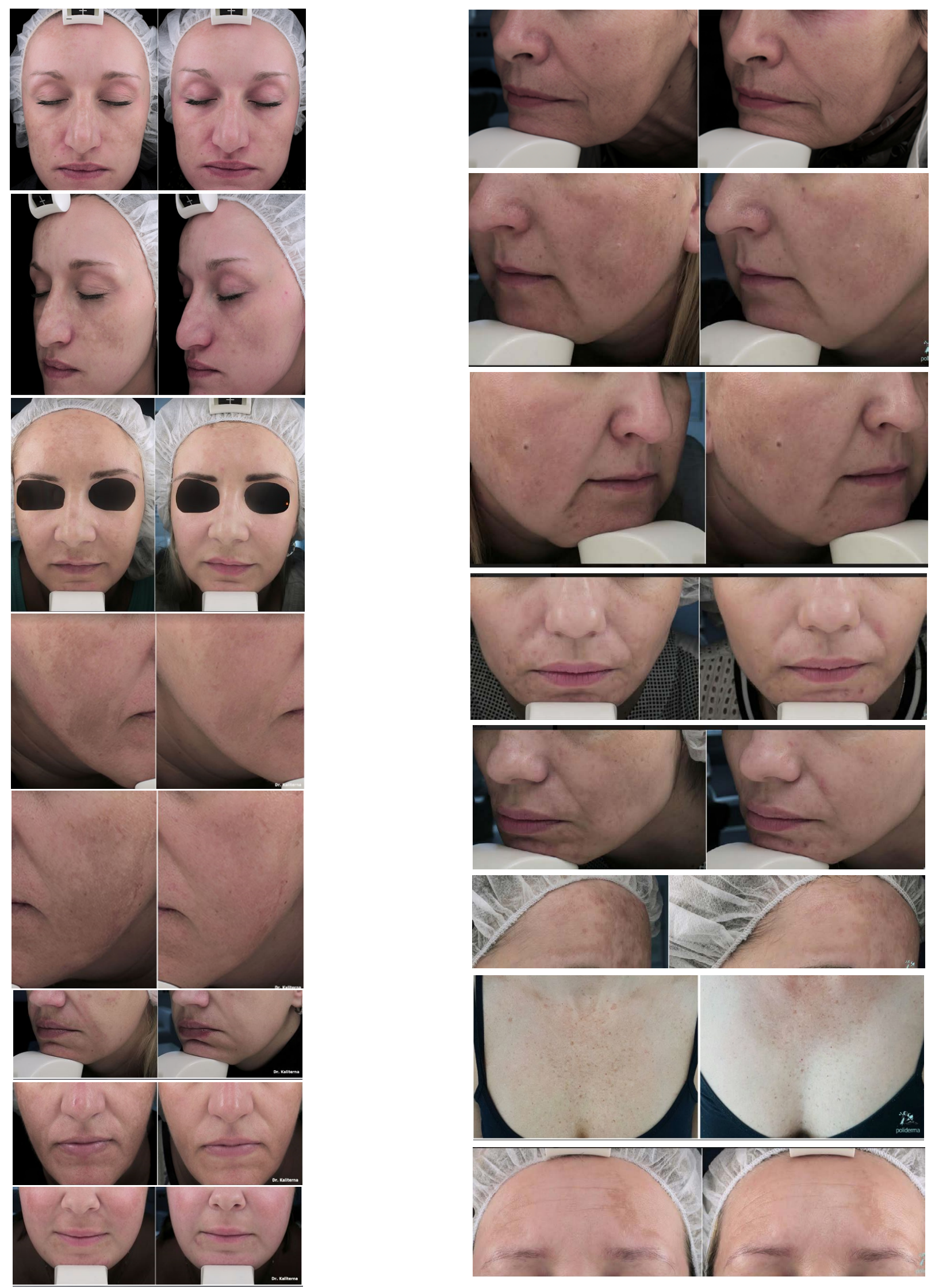

Figure 3. Images using VISIA on day 1 and day 30. 


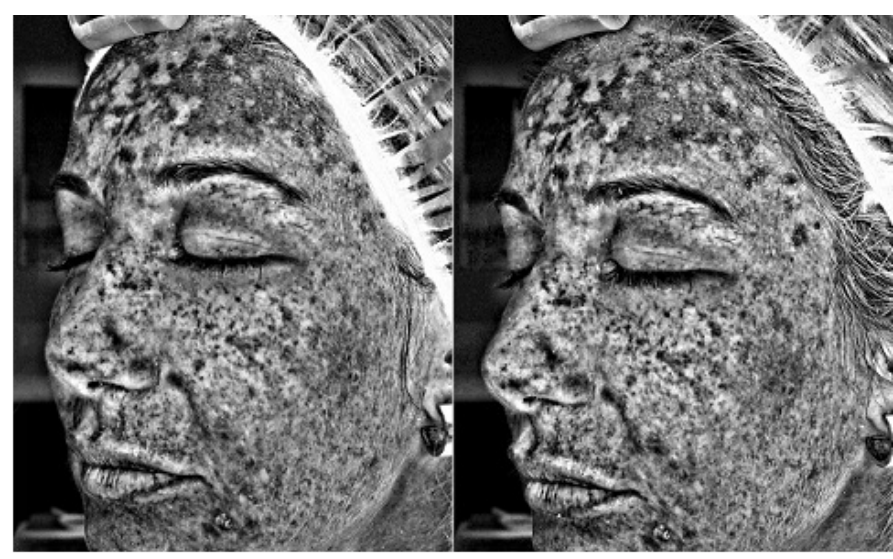

Figure 4. Image using VISIA analysis: reduction in superficial hyperpigmentation

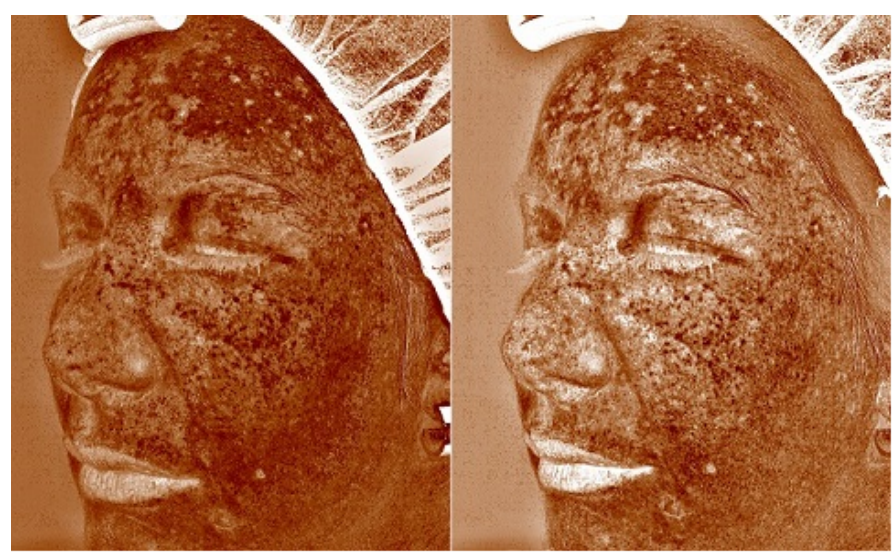

Figure 5. Image using VISIA analysis: reduction in deep hyperpigmentation

\section{Discussion}

4-n-Butylresorcinol is a resorcinol derivative that inhibits both tyrosinase and tyrosinase-related protein-1 (TRP-1) [1]. Its hypopigmenting action was first reported in 1995, and many following studies have documented its efficacy and safety in melasma treatment with the $0.1 \%$ cream, but there is paucity of clinical studies that used the $0.3 \%$ cream. The biochemical assay on inhibition of human tyrosinase activity has revealed the superiority of 4-n-butylresorcinol over other hypopigmenting agents $[42,43]$. Many studies show good efficacy and safety in treating melisma $[44,45]$.

\section{Conclusion}

Despite numerous treatment modalities available, due to its chronic and relapsing course, treating melasma still remains a challenge. Although hydroquinone and triple combination creams remain the gold standard of treatment, long term safety concerns and possible side effects warrant investigation of new, more efficacious and safer treatment modalities [46].

The investigated resorcinol derivative-based cream has shown the fastest onset of action (as measured by first reported improvements after 7-10 days) among all currently available topical preparations. Unlike other available topical preparations, this cream can be used throughout the year (including summer), the period of application is not limited (can be used continuously), and there are no pronounced side-effects (such as erythema or desquamation). In majority of cases, its effectiveness is better, and the results seen faster than with fractional laser. Its usage during pregnancy is not recommended, since no safety studies in this population were made.

Aside for its main purpose the reduction in hyperpigmentation, it has shown a strong rejuvenation effect. Accordingly, other indications for using this cream include premature signs of aging and sun damage, such as excessive redness, large pores, or uneven texture.

Taking into account its fast onset of action, once-a-day application, and a wide range of indications, this promising product may be a revolution both in treatment of melasma and in skin rejuvenation.

\section{References}

1. Shankar K, Godse K, Aurangabadkar S, Lahiri K, Mysore V, et al. (2014) Evidencebased treatment for melasma: expert opinion and a review. Dermatol Ther (Heidelb) 4 165-186. [Crossref]

2. Achar A, Rathi SK (2011) Melasma: a clinico-epidemiological study of 312 cases. Indian J Dermatol 56: 380-382. [Crossref]

3. Sanchez NP, Pathak MA, Sato S, et al. (1988) Melasma: a clinical, light microscopic, ultrastructural, and immunofluorescence study. J Am Acad Dermatol 4: 698.

4. Rodrigues M, Pandya AG4 (2015) Melasma: clinical diagnosis and management options. Australas J Dermatol 56: 151-163. [Crossref]

5. Sarkar R, Arora P, Garg VK, Sonthalia S, Gokhale N (2014) Melasma update. Indian Dermatol Online J 5: 426-435. [Crossref]

6. Elling SV, Powell FC (1997) Physiological changes in the skin during pregnancy. Clin Dermatol 15: 35-43. [Crossref]

7. Lee AY (2015) Recent progress in melasma pathogenesis. Pigment Cell Melanoma Res 28: 648-660. [Crossref]

8. Kang HY, Suzuki I, Lee DJ, et al. (2011) Transcriptional profiling shows altered expression of wnt pathway- and lipid metabolism-related genes as well as melanogenesis-related genes in melasma. J Invest Dermatol 131: 1692.

9. Kang HY, Hwang JS, Lee JY, Ahn JH, Kim JY, et al. (2006) The dermal stem cell factor and c-kit are overexpressed in melasma. Br J Dermatol 154: 1094-1099. [Crossref]

10. Kim EH, Kim YC, Lee ES, Kang HY (2007) The vascular characteristics of melasma J Dermatol Sci 46: 111-116. [Crossref]

11. Kim EJ, Park HY, Yaar M, Gilchrest BA (2005) Modulation of vascular endothelia growth factor receptors in melanocytes. Exp Dermatol 14: 625-633. [Crossref]

12. Grimes PE, Yamada N, Bhawan J (2005) Light microscopic, immunohistochemical, and ultrastructural alterations in patients with melasma. Am J Dermatopathol 27: 96.

13. Hernández-Barrera R, Torres-Alvarez B, Castanedo-Cazares JP, Oros-Ovalle C Moncada B (2008) Solar elastosis and presence of mast cells as key features in the pathogenesis of melasma. Clin Exp Dermatol 33: 305-308. [Crossref]

14. Kang HY, Suzuki I, Lee DJ, Ha J, Reiniche P, Aubert J, et al. (2011) Transcriptiona profiling shows altered expression of wnt pathway- and lipid metabolism-related genes as well as melanogenesis-related genes in melasma. J Invest Dermatol 2131:1692-1700.

15. Kang WH, Yoon KH, Lee ES, Kim J, Lee KB, et al. (2002) Melasma: histopathological characteristics in 56 Korean patients. Br J Dermatol 146: 228-237. [Crossref]

16. Rodrigues M, Pandya AG (2015) Melasma: clinical diagnosis and management options Australas J Dermatol 56: 151-163. [Crossref]

17. Majid I, Haq I, Imran S, Keen A, Aziz K, Arif T (2016) Proposing Melasma Severity Index: A New, More Practical, Office-based Scoring System for Assessing the Severity of Melasma Indian Journal of Dermatology 61: 39-44.

18. Martins VM, Sousa AR, Portela Nde C, Tigre CA, Gonçalves LM, et al. (2012) Exogenous ochronosis: case report and literature review. An Bras Dermatol 87: 633636. [Crossref]

19. Westerhof W, Kooyers TJ (2005) Hydroquinone and its analogues in dermatology - a potential health risk. J Cosmet Dermatol 4: 55-59. [Crossref]

20. Lowe NJ, Rizk D, Grimes P, Billips M, Pincus S (1998) Azelaic acid 20\% cream in the treatment of facial hyperpigmentation in darker-skinned patients. Clin Ther 20: 945 959. [Crossref] 
21. Verallo-Rowell VM, Verallo V, Graupe K, Lopez-Villafuerte L, Garcia-Lopez M. (1989) Double-blind comparison of azelaic acid and hydroquinone in the treatment of melasma. Acta Derm Venereol Suppl 143: 58-61.

22. Baliña LM, Graupe K (1991) The treatment of melasma. 20\% azelaic acid versus $4 \%$ hydroquinone cream. Int J Dermatol 30: 893-895. [Crossref]

23. Griffiths CE, Finkel LJ, Ditre CM, Hamilton TA, Ellis CN, et al. (1993) Topical tretinoin (retinoic acid) improves melasma. A vehicle-controlled, clinical trial. $\mathrm{Br} \mathrm{J}$ Dermatol 129: 415-421. [Crossref]

24. Rendon M, Berneburg M, Arellano I, Picardo M (2006) Treatment of melasma. J Am Acad Dermatol 54: S272-281. [Crossref]

25. Chan R, Park KC, Lee MH, et al. (2008) A randomized controlled trial of the efficacy and safety of a fixed triple combination (fluocinolone acetonide $0.01 \%$, hydroquinone $4 \%$, tretinoin $0.05 \%$ ) compared with hydroquinone $4 \%$ cream in Asian patients with moderate to severe melasma. Br J Dermatol 159: 697.

26. Taylor SC, Torok H, Jones T, Lowe N, Rich P, et al. (2003) Efficacy and safety of a new triple-combination agent for the treatment of facial melasma. Cutis 72: 67-72. [Crossref]

27. Gupta RR, Mahajan BB, Garg G (2001) Chemical peeling--evaluation of glycolic acid in varying concentrations and time intervals. Indian J Dermatol Venereol Leprol 67: 28-29. [Crossref]

28. Rendon MI, Berson DS, Cohen JL, Roberts WE, Starker I, et al. (2010) Evidence and considerations in the application of chemical peels in skin disorders and aesthetic resurfacing. J Clin Aesthet Dermatol 3: 32-43. [Crossref]

29. Kwon SH, Hwang YJ, Lee SK (2016) Heterogeneous Pathology of Melasma and Its Clinical Implications. Int J Mol Sci 17. [Crossref]

30. Chan NP, Ho SG, Shek SY, Yeung CK, Chan HH (2010) A case series of facial depigmentation associated with low fluence Q-switched 1,064 nm Nd:YAG laser for skin rejuvenation and melasma. Lasers Surg Med 42: 712-719. [Crossref]

31. Polnikorn N (2008) Treatment of refractory dermal melasma with the MedLite C6 Q-switched Nd:YAG laser: two case reports. J Cosmet Laser Ther 10: 167-173. [Crossref]

32. Wang CC, Hui CY, Sue YM, Wong WR, Hong HS (2004) Intense pulsed light for the treatment of refractory melasma in Asian persons. Dermatol Surg 30: 1196-1200. [Crossref]

33. Zhang X, Yang X, Yang H, Yang Y (2003) Study of inhibitory effect of acidum tranexamicum on melanin synthesis. Chin J Dermatovenerol Integr Tradit West Med. 2: $227-229$.
34. Kwon SH, Hwang YJ, Lee SK, et al. (2016) Heterogeneous Pathology of Melasma and Its Clinical Implications. Int J Mol Sci 17. [Crossref]

35. Dunn CJ, Goa KL (1999) Tranexamic acid: a review of its use in surgery and other indications. Drugs 57: 1005-1032. [Crossref]

36. Wu S, Shi H, Wu H, Yan S, Guo J, et al. (2012) Treatment of melasma with oral administration of tranexamic acid. Aesthetic Plast Surg 36: 964-970. [Crossref]

37. Kanechorn N, Ayuthaya P, Niumphradit N, Manosroi A, Nakakes A (2012) Topical 5\% tranexamic acid for the treatment of melasma in Asians: A double-blind randomized controlled clinical trial. J Cosmet Laser Ther 14: 150-154.

38. Lee JH, Park JG, Lim SH, Kim JY, Ahn KY, et al. (2006) Localized intraderma microinjection of tranexamic acid for treatment of melasma in Asian patients: A preliminary clinical trial. Dermatol Surg 32: 626-631.

39. Ubeid AA, Do S, Nye C, Hantash BM (2012) Potent low toxicity inhibition of human melanogenesis by novel indole-containing octapeptides. Biochim Biophys Acta 1820 1481-1489. [Crossref]

40. Hantash BM, Jimenez F (2009) A split-face, double-blind, randomized and placebocontrolled pilot evaluation of a novel oligopeptide for the treatment of recalcitrant melasma. J Drugs Dermatol 8:732-735.

41. Altaei T (2012) The treatment of melasma by silymarin cream. BMC Dermatol 12: 18 . [Crossref]

42. Kim DS, Kim SY, Park SH, Choi YG, Kwon SB, et al. (2005) Inhibitory effects of 4-n-butylresorcinol on tyrosinase activity and melanin synthesis. Biol Pharm Bull 28: 2216-2219. [Crossref]

43. Madan MN, Gowda A, Jaiswal AK (2016) Assessment of efficacy, safety, and tolerability of 4-n-butylresorcinol $0.3 \%$ cream: an Indian multicentric study on melasma. Clinical, Cosmetic and Investigational Dermatology 9: 21-27.

44. Huh SY, Shin JW, Na JI (2010) The efficacy and safety of 4-n-butylresorcinol $0.1 \%$ cream for the treatment of melasma: a randomized controlled split-face trial. Ann Dermatol 22: 21-25.

45. Khemis A, Kaiafa A, Queille-Roussel C, Duteil L, Ortonne JP (2007) Evaluation of efficacy and safety of rucinol serum in patients with melasma: a randomized controlled trial. Br J Dermatol 156: 997-1004. [Crossref]

46. Huh SY, Shin JW, Na JI, Huh CH, Youn SW, et al. (2010) Efficacy and safety of liposome-encapsulated 4-n-butylresorcinol $0.1 \%$ cream for the treatment of melasma: a randomized controlled split-face trial. J Dermatol 37: 311-315. [Crossref]

Copyright: $\mathbb{C} 2017$ Kaliterna D. This is an open-access article distributed under the terms of the Creative Commons Attribution License, which permits unrestricted use, distribution, and reproduction in any medium, provided the original author and source are credited. 